\title{
FONOAUDIOLOGIA E EDUCAÇÃO INFANTIL: UMA PARCERIA NECESSÁRIA
}

\section{Speech therapy and infantile education: a necessary partnership}

\author{
Poliana Carla Santos Maranhão (1), Sabrina Maria Pimentel da Cunha Pinto (2), \\ Cristiane Monteiro Pedruzzi ${ }^{(3)}$
}

\section{RESUMO}

Objetivo: investigar as informações que os professores de educação infantil possuem em relação a Fonoaudiologia na escola, bem como sobre temas ligados à área de linguagem. Métodos: foi aplicado um questionário, contendo 17 questões objetivas em uma amostra com 73 professores de educação infantil da rede municipal de ensino da cidade de Maceió-AL. Resultados: os participantes relacionaram a atuação fonoaudiológica na escola à presença de alterações no desenvolvimento da criança. $O$ índice de professores da amostra que obtiveram contato com o fonoaudiólogo na escola é de 4,1\%. Estes educadores relatam que apenas 57,5\% receberam informações sobre a aquisição de linguagem e o desenvolvimento da escrita. Conclusão: com a realização da presente pesquisa foi possível confirmar a necessidade de reforçar as ações fonoaudiológicas na escola, bem como a parceria entre fonoaudiólogos e professores.

DESCRITORES: Linguagem; Educação Infantil; Saúde Escolar

\section{INTRODUÇÃO}

A Fonoaudiologia no Brasil surgiu diretamente ligada à educação na década de 20 , com o intuito de padronizar a língua oficial do país que, segundo opiniões nacionalistas, encontrava-se contaminada pela diversidade cultural e dialetal oriundas dos movimentos migratórios da época ${ }^{1}$. Essas ações culminaram com a instauração dos cursos de nível superior, levando a Fonoaudiologia a se distanciar da educação e assumir um caráter clínico e tecnicista, tendo como foco de preocupação alterações já instaladas ${ }^{2}$.

A Fonoaudiologia, atualmente, volta a conquistar espaço junto à educação, assumindo esse ambiente como um vasto campo de atuação. O fonoaudiólogo na escola pode atuar na prevenção e na promoção de saúde. A Fonoaudiologia escolar visa à criação de condições favoráveis e eficazes

(1) Fonoaudióloga.

(2) Fonoaudióloga; Docente da Faculdade de Fonoaudiologia de Alagoas da Universidade Estadual de Ciências da Saúde de Alagoas, UNCISAL, Maceió, AL; Especialista em Linguagem pela Universidade Federal de Pernambuco.

(3) Fonoaudióloga; Psicóloga; Docente da Faculdade de Fonoaudiologia de Alagoas da Universidade Estadual de Ciências da Saúde de Alagoas, UNCISAL, Maceió, AL. para que as capacidades de cada um possam ser desenvolvidas ao máximo ${ }^{3,4}$.

O desenvolvimento da criança depende das oportunidades de aprendizagem oferecidas pelo mundo que a cerca. Ao ingressar na escola, a criança transpõe o limiar da família e passa a conviver com pessoas de sua idade, descobre novos valores e vivencia novas experiências. Para muitas delas, o convívio social proporcionado pela escola oferece possibilidades que a família, muitas vezes, não tem condições de oferecer ${ }^{5}$.

No Brasil, grande parte da população infantil que frequenta a escola pública apresenta precárias condições de sobrevida e, frequentemente, tem seus pais com baixo nível de instrução ${ }^{6}$. Assim, o professor assume um papel fundamental na educação infantil, pois the cabe a responsabilidade de propiciar oportunidades de aprendizagem no âmbito escolar, e, nesse contexto, a linguagem ocupa um espaço fundamental devido a sua importância para a formação do sujeito ${ }^{7,8}$.

A escola é um lugar privilegiado para a aquisição da linguagem, sendo esse o espaço ideal para a atuação primária do fonoaudiólogo ${ }^{9}$. A criança na faixa etária de zero a seis anos se encontra em plena expansão de áreas que contribuirão para aquisições tardias mais complexas. Diante disso, a 
atuação do fonoaudiólogo junto às escolas de educação infantil torna-se importante, pois é na préescola que as crianças aperfeiçoam a linguagem oral e desenvolvem importantes noções de escrita ${ }^{10}$. Nesse nível de escolaridade, a atuação do fonoaudiólogo pode ter resultados mais produtivos porque a criança está em um período de rápidas e significativas transformações em vários aspectos do seu desenvolvimento ${ }^{11}$.

O professor tem papel de destaque no processo ensino-aprendizagem e com uma assessoria fonoaudiológica, que esteja compondo um trabalho de formação continuada, pode ser um forte aliado para a elaboração de estratégias de incentivo das habilidades comunicativas dos alunos e identificação o quanto antes dos desvios apresentados por eles ${ }^{12,13}$

Os educadores observam, algumas vezes, que há alunos que não apresentam o desempenho escolar esperado, atribuíndo-lhes uma condição de dificuldade de aprendizagem. Quando o professor mantém uma formação continuada, com uma equipe multidisciplinar, na qual o fonoaudiólogo deve fazer parte, estas diferenças na evolução da turma podem ser abordadas e redimensionadas. Isto muitas vezes, modifica as estratégias utilizadas pelos professores, assim como, a orientação para o encaminhamento das crianças que necessitam de uma intervenção clínica ${ }^{4,11,14}$.

A Fonoaudiologia, ao compartilhar de seus conhecimentos sobre prevenção, aquisição e desenvolvimento de linguagem com os professores, trará benefícios ilimitados ao ambiente escolar ${ }^{15,16}$. A parceria entre o professor e o fonoaudiólogo tornase fundamental, uma vez que o professor está em contato mais próximo e constante com a criança ${ }^{17}$.

No Brasil, ainda são poucas as escolas que incluem oficialmente no seu quadro profissional o fonoaudiólogo. Assim, a proposta do presente estudo foi investigar as informações que os professores de educação infantil possuem em relação a Fonoaudiologia na escola, bem como sobre temas ligados à área de linguagem.

\section{MÉTODOS}

A pesquisa foi desenvolvida em oito escolas de educação infantil da rede municipal de ensino da cidade de Maceió-AL e contou com a participação de 73 professores do sexo feminino, na faixa etária entre 20 e 56 anos. Foram incluídos neste estudo, os professores de educação infantil em exercício na rede municipal de ensino, que aceitaram participar da pesquisa mediante a assinatura do termo de Consentimento Livre e Esclarecido e autorização da direção escolar.
Após o consentimento em participar do estudo, os professores receberam um questionário previamente elaborado pela pesquisadora com base na literatura especializada. O questionário era composto por 17 questões. As questões iniciais (as seis primeiras questões) tiveram como objetivo a identificação do profissional com relação a sua formação acadêmica (formação, tempo de formado, cursos realizados). As demais questões (da $7^{\underline{a}}$ até a $17^{\mathrm{a}}$ ) procuraram averiguar que informações os professores possuíam em relação a Fonoaudiologia Educacional e a temas ligados a área de linguagem que podem interferir no processo ensino-aprendizagem dos educandos. Por exemplo: Você recebeu informações sobre o trabalho fonoaudiológico; Você já teve contato com algum fonoaudiólogo atuando na escola? Quais patologias fonoaudiológicas você já viu ou ouviu falar dentro da escola em que trabalha? Você já recebeu alguma informação sobre aquisição e desenvolvimento de linguagem? Qual o seu procedimento quando detecta algum distúrbio como os acima citados? Você acha importante a atuação do fonoaudiólogo no ambiente escolar, Por quê?

O questionário foi aplicado na instituição de ensino de cada participante, em horário cedido pela direção da escola. Após a explicação desse, pela pesquisadora, foi solicitado que os professores respondessem o questionário individualmente e sem consulta, evitando assim, a possível interferência de outros em suas respostas. Todas as questões foram de múltipla escolha, sendo permitido que os professores assinalassem mais de uma resposta, se julgassem necessário. $O$ tempo médio para o preenchimento do questionário foi de 15 minutos, estando à pesquisadora presente durante esse período.

O Comitê de Ética em Pesquisa da Universidade Estadual de Ciências da Saúde de Alagoas UNCISAL aprovou esta pesquisa sob o protocolo de número 609.

Os resultados da pesquisa foram analisados descritivamente por meio do cálculo de médias e proporções. Utilizou-se $\mathrm{o}$ teste $\mathrm{Z}$ de análise de amostras independentes e o teste $\mathrm{T}$ de Student (dependendo do número de amostras) para realizar a análise dos resultados obtidos. O nível de significância adotado foi de 5\%.

Os dados colhidos foram armazenados e analisados com o auxílio do programa Excel $2002 \AA$ (Microsoft corporation). Foram calculadas as frequências específicas das variáveis e as médias, em seguida, criadas tabelas binomiais com cruzamentos entre as variáveis estudadas. Os testes $\mathrm{Z}$ e $T$ de Student para amostras independentes foram utilizados para comparação de proporções, sendo avaliado se existia ou não diferenças significantes entre 
as proporções de respostas fornecidas, categorizadas de acordo com a formação e experiência dos participantes. A escolha entre o teste $Z$ e o teste $T$ de Student dependeu do número de amostras encontradas. O grau de significância (valor de $p$ ) foi utilizado para quantificar a possibilidade dos números observados apresentarem distribuição ao acaso. Considerou-se como significante um valor menor do que $5 \%(p<0,05)$.

\section{RESULTADOS}

A faixa etária dos pesquisados encontra-se entre 20 e 56 anos, perfazendo uma média de 37,14 anos, com desvio padrão de 8,21. Quanto à escolaridade, 21 professores $(28,8 \%)$ têm curso de magistério; nove $(12,3 \%)$ estão cursando uma faculdade; 24 (32,9\%) possuem curso superior completo, sendo 21 graduados em pedagogia, dois em letras e um em história; e 19 (26,0\%) possuem curso de pós-graduação, oito em psicopedagogia, cinco em educação infantil, três em docência do ensino superior, dois em coordenação pedagógica e um em gestão educacional. A Tabela 1 apresenta a escolaridade dos professores e o tempo que eles têm de formado.

Conforme observado na Figura 1, 38 (53,4\%) professores referem conhecer o trabalho fonoaudiológico, enquanto $35(49,3 \%)$ negam conhecêlo. Ao ser aplicado o teste estatístico Z, observase a não significância em relação a esses dados $(p=0,3632)$.

Na Figura 2, observa-se que apenas três $(4,1 \%)$ professores tiveram contato com algum fonoaudiólogo na escola, dado significante segundo teste estatístico $Z$ ( $p=0,0001)$. Apesar desse dado, os $73(100 \%)$ participantes afirmam que a atuação do fonoaudiólogo na escola é importante.

Tabela 1 - Escolaridade e tempo de formação dos professores

\begin{tabular}{lcccccc}
\hline \multirow{2}{*}{$\begin{array}{l}\text { Tempo de } \\
\text { formação }\end{array}$} & $\begin{array}{c}\text { Ensino } \\
\text { médio }\end{array}$ & Magistério & $\begin{array}{c}\text { Superior em } \\
\text { Andamento }\end{array}$ & $\begin{array}{c}\text { Superior } \\
\text { completo }\end{array}$ & $\begin{array}{c}\text { Pós- } \\
\text { graduação }\end{array}$ & TOTAL \\
\hline O a 3 anos & $0,0 \%$ & $4,3 \%$ & $30,4 \%$ & $34,8 \%$ & $30,4 \%$ & $\mathbf{3 1 , 5 \%}$ \\
4 a 8 anos & $0,0 \%$ & $35,0 \%$ & $5,0 \%$ & $40,0 \%$ & $20,0 \%$ & $\mathbf{2 7 , 4 \%}$ \\
9 a 12 anos & $0,0 \%$ & $25,0 \%$ & $0,0 \%$ & $37,5 \%$ & $37,5 \%$ & $\mathbf{1 1 , 0 \%}$ \\
13 a 20 anos & $0,0 \%$ & $50,0 \%$ & $0,0 \%$ & $8,3 \%$ & $41,7 \%$ & $\mathbf{1 6 , 4 \%}$ \\
mais de 20 anos & $0,0 \%$ & $50,0 \%$ & $10,0 \%$ & $40,0 \%$ & $0,0 \%$ & $\mathbf{1 3 , 7 \%}$ \\
\hline TOTAL & $\mathbf{0 , 0 \%}$ & $\mathbf{2 8 , 8 \%}$ & $\mathbf{1 2 , 3 \%}$ & $\mathbf{3 2 , 9 \%}$ & $\mathbf{2 6 , 0 \%}$ & $\mathbf{1 0 0 , 0 \%}$ \\
\hline
\end{tabular}

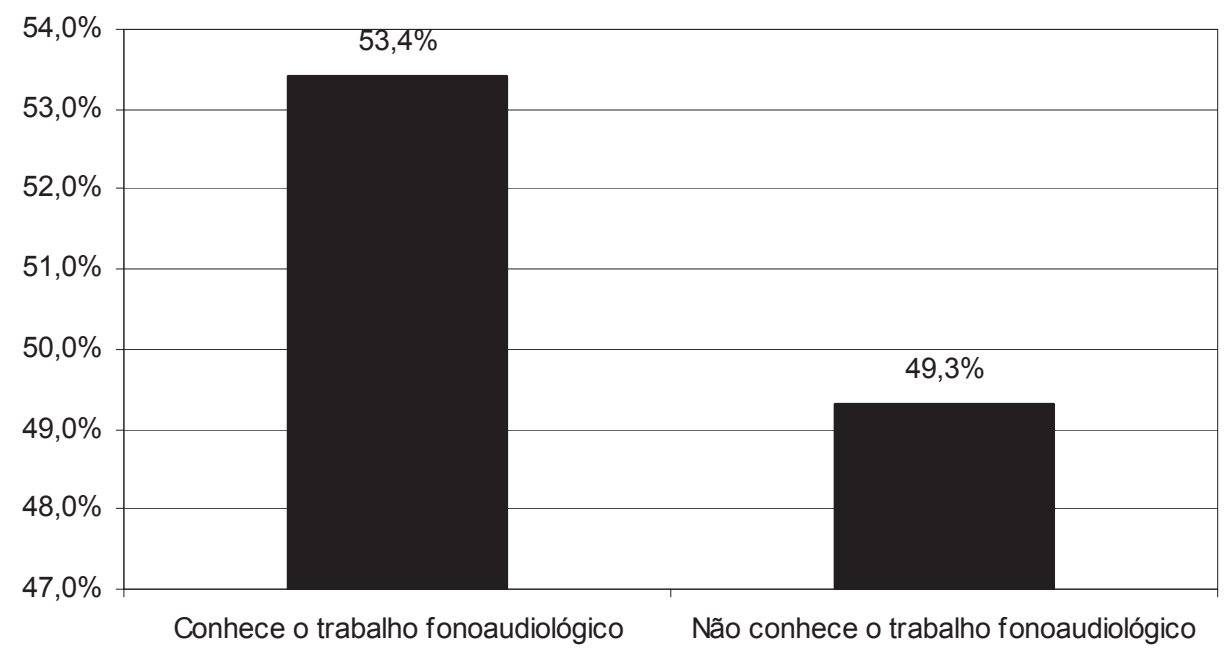

Figura 1 - Distribuição da amostra dos professores segundo o conhecimento do trabalho fonoaudiológico 


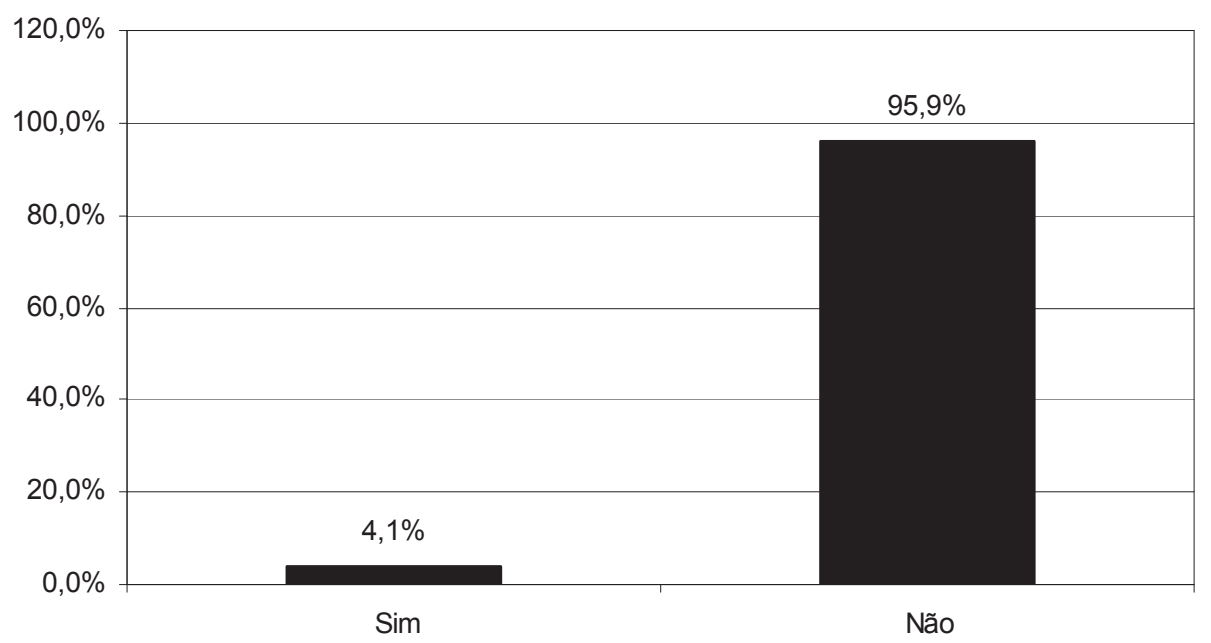

Figura 2 - Distribuição da amostra dos professores segundo o contato com fonoaudiólogo na escola

A Tabela 2 revela a opinião dos professores quanto à atuação do fonoaudiólogo no âmbito escolar, tendo a maioria, $(67,1 \%)$ referido que a atuação do fonoaudiólogo na escola é importante para realizar atendimento aos alunos que apresentam alterações.

Como é possível visualizar na Figura 3, 42 $(57,5 \%)$ participantes já receberam informações sobre aquisição de linguagem $(p=0,0985)$. Desses, $18(42,9 \%)$ receberam informações por meio de palestras; seis $(14,3 \%)$ através de literatura especializada; 25 (59,5\%) em cursos; 10 (23,8\%) na graduação e dois $(4,8 \%)$ por outros meios.

As patologias mais frequentes na escola, segundo os professores, são: atraso de linguagem, $43(58,9 \%)$ professores revelaram ter tido contato com alunos apresentando tal patologia; seguida por Transtorno do Déficit de Atenção e Hiperatividade (TDAH) $(\mathrm{N}=41 ; 56,2 \%)$; gagueira $(\mathrm{N}=40 ; 54,8 \%)$; desvio fonológico $(\mathrm{N}=22 ; 30,1 \%)$ e autismo $(\mathrm{N}=11$; $15,1 \%)$, como pode ser verificado na Figura 4.

A maioria dos professores $(\mathrm{N}=71 ; 97,2 \%)$ afirma a importância de receber orientações específicas sobre como agir com alunos que apresentam alte- rações de linguagem. A Tabela 3 revela os procedimentos realizados pelos professores quando detectam alguma alteração no desenvolvimento do aluno, observando-se que $49(67,1 \%)$ deles tentam auxiliar a criança em sala de aula.

Com relação aos conhecimentos dos professores frenteàs patologias encontradas na escola(Figura 5), sete $(9,6 \%)$ declararam saber o que é atraso de linguagem; 55 (75,3\%) saber um pouco e $11(15,1 \%)$ referiram não saber nada sobre 0 assunto. Em relação ao desvio fonológico, dois (2,7\%) afirmaram saber o que é; $52(71,2 \%)$ saber um pouco sobre o assunto e $19(26,0 \%)$ não saber do que se trata. Quando o assunto é gagueira, $19(26,0 \%)$ julgam-se saber sobre o assunto; 49 (67,1\%) saber um pouco e cinco $(6,8 \%)$ não saber. Em relação ao autismo, oito $(11,0 \%)$ afirmam saber sobre o assunto; 49 $(67,1 \%)$ saber um pouco e $16(21,9 \%)$ não saber de que se trata. Já em relação ao TDAH, oito $(11,0 \%)$ referiram saber sobre o assunto; $56(76,7 \%)$ saber um pouco e nove (12,3\%) não saber. Na Tabela 4, pode ser observado o conhecimento dos professores em relação às patologias encontradas na escola e a sua formação.

Tabela 2 - Respostas dos professores quanto à atuação do fonoaudiólogo no âmbito escolar

\begin{tabular}{lc}
\hline Atuação do fonoaudiólogo & Porcentagem \\
\hline Auxiliar o trabalho do professor & $58,9 \%$ \\
Não tem relação & $0,0 \%$ \\
Detectar e encaminhar os alunos que apresentam dificuldades & $45,2 \%$ \\
Realizar atendimento dos alunos que apresentam alterações & $67,1 \%$ \\
Planejar as atividades junto com a equipe escolar & $31,5 \%$ \\
Realizar orientações e palestras para pais e professores & $57,5 \%$ \\
Prevenir alterações & $24,7 \%$ \\
\hline
\end{tabular}




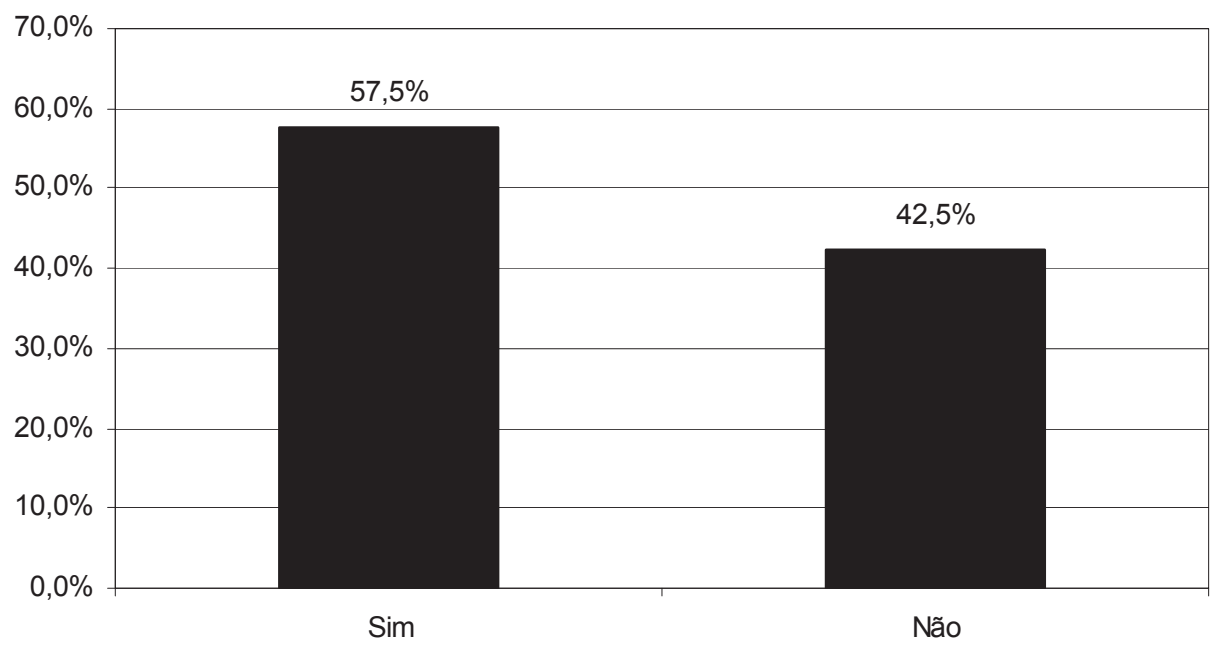

Figura 3 - Distribuição percentual dos professores que receberam informações sobre aquisição de linguagem

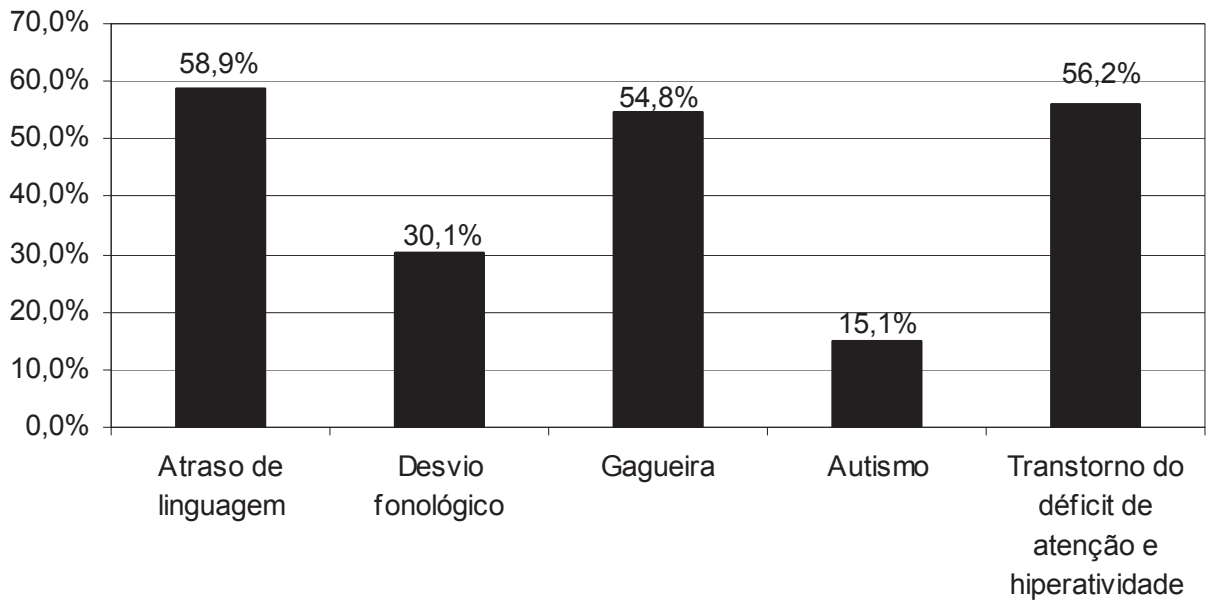

(TDAH)

Figura 4 - Respostas dos professores em relação às patologias encontradas dentro da escola

Tabela 3 - Procedimentos que o professor adota quando detecta algum distúrbio

\begin{tabular}{lc}
\hline Procedimento adotado & Porcentagem \\
\hline Encaminha para um fonoaudiólogo & $16,4 \%$ \\
Encaminha para um psicopedagogo & $27,4 \%$ \\
Tenta auxiliar a criança em sala de aula & $67,1 \%$ \\
Orienta os pais para auxiliar a criança em casa & $50,7 \%$ \\
Encaminha para os centros de atendimento municipal & $32,9 \%$ \\
\hline
\end{tabular}

\section{DISCUSSÃO}

Os professores $(53,4 \%)$ declaram conhecer o trabalho fonoaudiológico, contudo, eles não especificam que este trabalho esteja voltado para as áreas de prevenção e promoção de saúde. Esse dado pode ser justificado pelo fato de apenas 4,1\% dos professores, dado significante, terem entrado em contato com algum fonoaudiólogo na escola, demonstrando que a atuação fonoaudiológica nesse âmbito ainda é recente ${ }^{18}$.

A pesquisa mostra que, apesar de $49,3 \%$ dos professores negarem conhecer o trabalho fonoaudiológico, todos eles julgaram a atuação do 


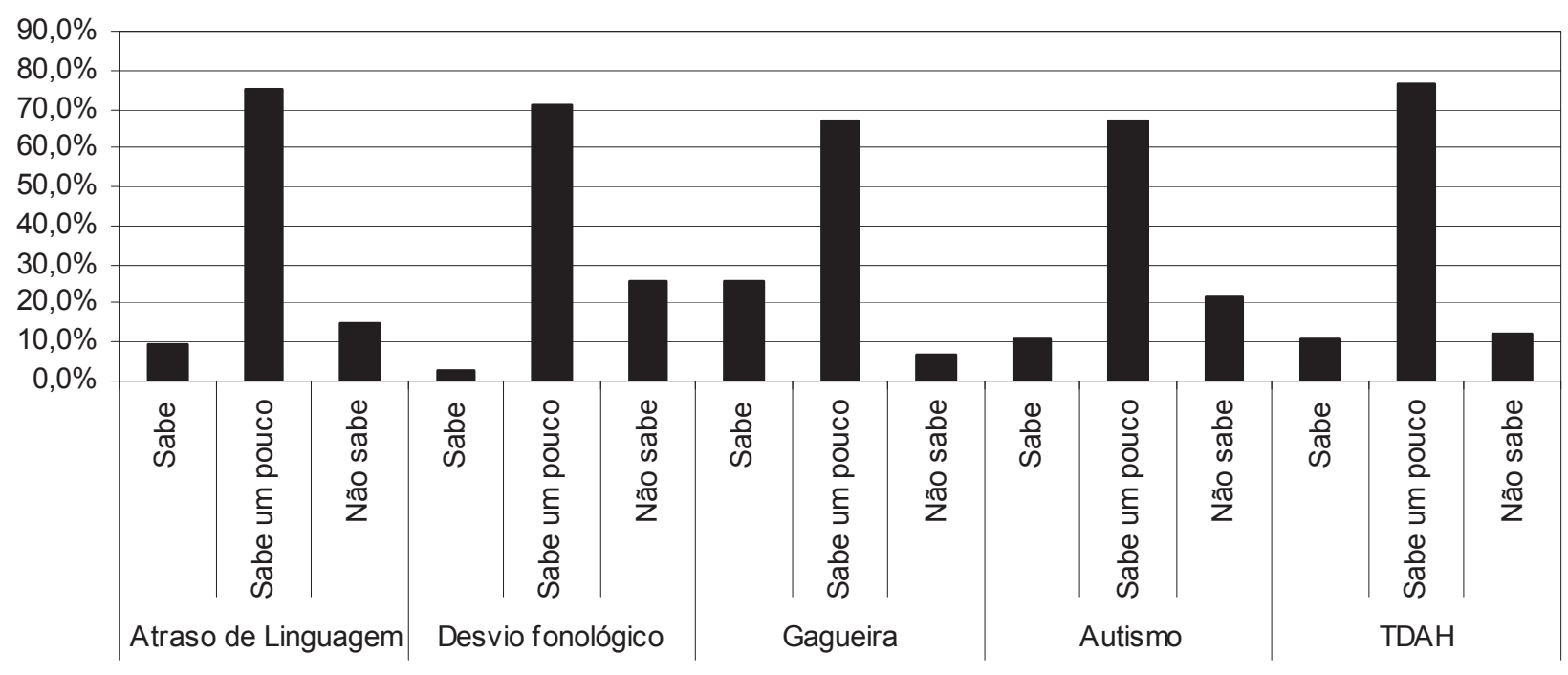

Figura 5 - Distribuição percentual das respostas dos professores frente às patologias encontradas na escola

Tabela 4 - Respostas apresentadas pelos professores em relação às patologias encontradas na escola e sua formação

\begin{tabular}{lcccccc}
\hline Patologias & Respostas & $\begin{array}{c}\text { Ensino } \\
\text { médio }\end{array}$ & Magistério & $\begin{array}{c}\text { Superior em } \\
\text { andamento }\end{array}$ & $\begin{array}{c}\text { Superior } \\
\text { completo }\end{array}$ & $\begin{array}{c}\text { Pós- } \\
\text { graduação }\end{array}$ \\
\hline Atraso de & Sabe & $0,0 \%$ & $14,3 \%$ & $11,1 \%$ & $8,3 \%$ & $5,3 \%$ \\
Linguagem & Sabe um pouco & $0,0 \%$ & $76,2 \%$ & $77,8 \%$ & $70,8 \%$ & $78,9 \%$ \\
& Não sabe & $0,0 \%$ & $9,5 \%$ & $11,1 \%$ & $20,8 \%$ & $15,8 \%$ \\
\hline \multirow{2}{*}{ Desvio } & Sabe & $0,0 \%$ & $0,0 \%$ & $0,0 \%$ & $4,2 \%$ & $5,3 \%$ \\
fonológico & Sabe um pouco & $0,0 \%$ & $95,2 \%$ & $66,7 \%$ & $50,0 \%$ & $73,7 \%$ \\
& Não sabe & $0,0 \%$ & $4,8 \%$ & $33,3 \%$ & $45,8 \%$ & $21,1 \%$ \\
\multirow{2}{*}{ Gagueira } & Sabe & $0,0 \%$ & $33,3 \%$ & $33,3 \%$ & $20,8 \%$ & $21,1 \%$ \\
& Sabe um pouco & $0,0 \%$ & $57,1 \%$ & $55,6 \%$ & $70,8 \%$ & $78,9 \%$ \\
\multirow{2}{*}{ Autismo } & Não sabe & $0,0 \%$ & $9,5 \%$ & $11,1 \%$ & $8,3 \%$ & $0,0 \%$ \\
\hline \multirow{2}{*}{ TDAH } & Sabe & $0,0 \%$ & $14,3 \%$ & $11,1 \%$ & $8,3 \%$ & $10,5 \%$ \\
& Sabe um pouco & $0,0 \%$ & $57,1 \%$ & $77,8 \%$ & $70,8 \%$ & $68,4 \%$ \\
& Não sabe & $0,0 \%$ & $28,6 \%$ & $11,1 \%$ & $20,8 \%$ & $21,1 \%$ \\
\hline & Sabe & $0,0 \%$ & $9,5 \%$ & $22,2 \%$ & $12,5 \%$ & $5,3 \%$ \\
& Sabe um pouco & $0,0 \%$ & $66,7 \%$ & $55,6 \%$ & $79,2 \%$ & $94,7 \%$ \\
& Não sabe & $0,0 \%$ & $23,8 \%$ & $22,2 \%$ & $8,3 \%$ & $0,0 \%$ \\
\hline
\end{tabular}

Teste $T$ de student para amostras independentes (correlacionando dois a dois) $\mathrm{p}$-valor (valor médio de $\mathrm{p}$ ) $=0.2865$

fonoaudiólogo na escola importante, referindo à intervenção no âmbito clínico. Conforme a revisão de literatura, este fato justifica-se pela própria origem dos cursos de fonoaudiologia que inicialmente surgiram como uma área da educação e posteriormente foram vinculados as faculdades de medicina. Confirmando este dado, observou-se que $67,1 \%$ dos professores relacionam a atuação fonoaudiológica na escola a ações terapêuticas. Novamente, o fato remete a própria história da Fonoaudiologia na escola, que em seus primórdios dirigia o enfoque para atuação clínica em distúrbios já instalados ${ }^{18-20}$.

A Fonoaudiologia trilha novos caminhos na sua atuação escolar, a Tabela 2 apresenta indícios do reconhecimento dos professores nesse sentido, onde o foco é a normalidade e não a patologia. A literatura salienta a importância de os professores reconhecerem que o fonoaudiólogo na escola é um 
educador em saúde, portanto deve promover ações junto aos professores que evitem ou minimizem o fracasso escolar ${ }^{12}$.

Conforme os resultados relatados, observa-se que, embora os professores apresentem formação específica para atuar em Educação, ainda necessitam de informações complementares no que concerne a aspectos de linguagem. Apenas $57,5 \%$ dos professores afirmaram ter recebido informações sobre aquisição de linguagem. Dado preocupante em virtude desta população atuar junto a crianças em processo de aquisição de linguagem.

Os professores detectam na escola, índices elevados de patologias/alterações. Dados que podem ser contestados tendo em vista o pouco conhecimento que eles demonstram ter sobre o assunto. Diante da análise, percebe-se a importância de se pensar em meios para que os conhecimentos do fonoaudiólogo possam vir a contribuir para o ambiente escolar, no sentido de que os professores, ao invés de rotularem seus alunos, possam compreendê-los e ter subsídios para identificar patologias, sabendo lidar com elas.

Mesmo diante das carências de informações evidenciadas, a maioria dos professores tenta auxiliar as crianças que apresentam dificuldades.
Apenas 10 a 20\% dos problemas de aprendizagem encontrados dentro das escolas são exclusivos dos alunos e 80 a $90 \%$ tem a causa ligada a questões culturais, sociais e políticas. A postura/atitude do professor tem um peso significativo na produção do fracasso ou sucesso escolar ${ }^{21}$.

O objetivo da pesquisa era investigar as informações que os professores de educação infantil possuem em relação a Fonoaudiologia na escola, bem como sobre temas ligados à área de linguagem. Por isso, podemos inferir que os educadores possuem uma idéia genérica sobre a prática fonoaudiológica na escola e aos temas relacionados à linguagem.

\section{CONCLUSÃO}

Com a realização da presente pesquisa foi possível confirmar a necessidade de reforçar as ações fonoaudiológicas na escola, bem como a parceria entre fonoaudiólogos e professores. Uma vez que foi percebido o pouco conhecimento dos professores em relação à atuação fonoaudiológica na escola, bem como a temas ligados a linguagem, o que poderá interferir no processo ensino-aprendizagem do aluno.

\section{ABSTRACT}

Purpose: to investigate the knowledge of infantile education teachers about the speech therapy at school, as well as on subjects regarding language area. Methods: 73 infantile education teachers in public schools of Maceió-AL answered a questionnaire containing 17 objective questions. Results: the participants related the performance of speech therapy staff at schools to the presence of alterations in children development. Only $4.1 \%$ of the teachers have had contact with some speech therapist at school. These educators report that only $57.5 \%$ received information about language acquisition and development of writing. Conclusion: upon accomplishing this research it was possible to confirm the necessity for reinforcing speech therapy related actions in school, as well as the partnership among speech therapists and teachers.

KEYWORDS: Language; Child Rearing; School Health

\section{REFERÊNCIAS}

1. Berberian AP. Fonoaudiologia e educação: um encontro histórico. São Paulo: Summus; 2000. $155 \mathrm{p}$.

2. Bacha SMC, Osório AMN. Fonoaudiologia e educação: uma revisão da prática histórica. Rev CEFAC. 2004; 6(2):215-21.

3. Zorzi JL. Possibilidades de trabalho do fonoaudiólogo no âmbito escolar-educacional. J Cons Fed Fonoaudiol. 1999; 4(2):211-7.
4. Luzardo R, Nemr K. Instrumentalização fonoaudiológica para professores da educação infantil. Rev CEFAC. 2006; 8(3):289-300.

5. Costa MG. Fonoaudiólogo e o professor de educação infantil uma relação viva [monografia]. São Paulo (SP): CEFAC - Saúde e Educação; 1999.

6. Kappel MDB, Carvalho MC, Kramer S. Perfil das crianças de 0 a 6 anos que freqüentam creches, pré-escolas e escolas: uma análise dos resultados da pesquisa sobre padrões de vida/IBGE. Rev Bras Educ. 2001; 16:35-47. 
7. Brasil. Ministério da Educação e do Desporto, Secretaria da Educação fundamental. Referencial curricular nacional para a educação infantil. vol 1. Brasília (DF): MEC/SEF;1998.

8. Rocato CC, Lacerda CBF. Possibilidades de desenvolvimento de linguagem no espaço da educação infantil. Dist Comun. 2005; 17(2):215-23.

9. Silveira PCM, Cunha DA, Fontes ML, Lima AEB, Farias PS, Lucena JA. A importância da prevenção à gagueira nas escolas. Fono Atual. 2002; 5(22):12-27.

10. Balestrin CA, Cielo CA. O professor pré-escolar e sua prática em consciência fonológica. Rev Soc Bras Fonoaudiol. 2003; 8(1):27-33.

11. Simões JM, Assencio-Ferreira VJ. Avaliação de aspectos da intervenção fonoaudiológica junto a um sistema educacional. Rev CEFAC. 2002; 4(2):97-104.

12. Brasil CCP, Chiari BM. Integrando fonoaudiologia e escola: uma proposta para prevenção do distúrbio de leitura e escrita. Fono Atual. 2006; 36(9):35-43.

13. Maas W. Early detection of speech and language delays in the Netherlands. The case for integrating primary and secondary prevention. Child Care Health Dev. 2000; 26(2):150-62.

14. Nascente VP, França MP. Estudo de prevalência de alterações na aquisição fonológica em préescolares e escolares. Rev Fonoaudiol Bras. 2005; 3:11-4.
15. Zorzi JL. Fonoaudiologia e educação: encontros, desencontros e a busca de uma atuação conjunta. In: Zorzi JL. Aprendizagem e distúrbios da linguagem escrita: questões clínicas e educacionais. Porto Alegre: Artmed; 2003. p. 157-71.

16. Morais KW. Repensar sobre o papel do fonoaudiólogo no âmbito escolar [periódico online]. 2001. Disponível em:

http://www.fonoaudiologia.com/trabalhos/artigos/ artigo-035/index.htm

17. Sacaloski M, Alavarsi E, Guerra GR. Fonoaudiólogo e professor: uma parceria fundamental. In: Sacaloski M, Alavarsi E, Guerra GR. Fonoaudiologia na escola. São Paulo: Lovise; 2000. p. 19-24.

18. Wippel MLM, Fadanelli APR. A prática da fonoaudiologianaescolanavisãodosfonoaudiólogos e professores atuantes na rede municipal de ensino de Curitiba. J Bras Fonoaudiol. 2003; 4(14):21-31.

19. Cavalheiro MTP. Reflexões sobre a relação entre a fonoaudiologia e a educação. In: Giroto CRM. Perspectivas atuais da fonoaudiologia na escola. São Paulo: Plexus; 1999. p. 11-23.

20. Calheta PP. Fonoaudiologia e Educação: sentidos do trabalho de assessoria a escolas públicas. In: César CPHAR, Calheta PP. Assessoria e Fonoaudiologia: perspectiva de ações. Rio de Janeiro: Revinter; 2005. p.103-15.

21. Bacha SMC, Brandão CCRD, Sauer L, Bednaski AV, Camparoto MY. Rendimento escolar de alunos da área rural em escola urbana. Rev CEFAC. 2006; 8(4):429-40.

DOI: 10.1590 / S1516-18462008005000006

RECEBIDO EM: 16/08/2007

ACEITO EM: 08/08/2008

Endereço para correspondência:

Poliana Carla Santos Maranhão

Rua O, Qd. H, 47, Conj. Henrique Equelman

Maceió - AL

CEP: 57084-030

E-mail: polimaranhao@yahoo.com.br 